\title{
POTENTIAL AGENTS FOR ERADICATION OR CONTROL OF GYPSY MOTH IN NEW ZEALAND
}

\author{
T.R. GLARE ${ }^{1}$, N.D. BARLOW ${ }^{1}$ and P.J. WALSH ${ }^{2}$ \\ ${ }^{1}$ AgResearch, PO Box 60, Lincoln, New Zealand \\ ${ }^{2}$ Forest Research Associates, PO Box 1031 Rotorua
}

\begin{abstract}
Gypsy moth, Lymantria dispar, poses a major threat to New Zealand forests, especially the "Asian" strain, which has characteristics such as female flight and reduced diapause requirements for egghatching. To combat the threat, we have reviewed control options, particularly biological agents, used overseas and how they might be used in New Zealand for eradication and population suppression of gypsy moth. Our research has included molecular typing, safety testing of biologicals, and the development of tactical and strategic models. The most promising agent for eradication is Bacillus thuringiensis var. kurstaki and, for suppression, a nucleopolyhedrovirus and the fungus Entomophaga maimaiga.
\end{abstract}

Keywords: Lymantria dispar, gypsy moth, biological control, insect pathogens, insect growth regulator.

\section{INTRODUCTION}

Gypsy moth (GM), Lymantria dispar L. (Lepidoptera: Lymantriidae), comprises a number of "strains" which are native to much of Eurasia and North Africa and a serious pest of forests throughout the northern hemisphere. GM attacks over 500 species, including many significant forest trees (USDA 1995). While the preferred hosts are oak, apple, sweetgum, speckled alder, basswood, birch, poplar and willow, the larvae will feed on almost any plant when the larval population is sufficiently high. The moth is also an urban pest because it attacks ornamental trees and the hairs of the larvae cause allergic responses in humans. An 'Asian' strain of gypsy moth (AGM) has recently spread across Asia and Europe; this strain is potentially even more damaging than the European (EGM) and North American (NAGM) strains. Females of AGM can fly (EGM and NAGM strains cannot), are attracted to light and have a wider host range. A proportion of AGM eggs do not undergo obligatory diapause and they hatch over a longer period, increasing the chance of introduction to new environments. Some of these characteristics have enabled AGM to survive transport across the equator, threatening southern hemisphere countries, while the recent discovery of viable AGM egg masses on ships in New Zealand ports has raised awareness of the danger. Risk assessment (Cowley et al. 1993) concluded that it is almost inevitable that GM will reach New Zealand and that it would be a serious pest of forests.

In 1993, a programme was initiated to investigate biological control options of GM strains for New Zealand, funded by the Foundation for Research, Science and Technology. Herein, we briefly summarise methods and agents for use against GM, suitable for New Zealand. Efforts to control a GM outbreak could take two forms: eradication, where a population contained in small area is treated with agent(s) to kill every individual; or introduction of agent(s) for long term suppression. Population suppression would be used if eradication failed or the original incursion had spread too far for eradication. The two approaches are not exclusive and agents suitable for suppression could be introduced during an eradication campaign. 


\section{IDENTIFICATION OF GYPSY MOTH STRAINS}

Much of the risk assessment and subsequent planning in New Zealand for response to GM has been based on the Asian strain. The requirements for control of an incursion of AGM would be different to that of the non-flighted strains of GM, as some agents (eg pheromones) would not be as effective against widely spreading moths. However rapid identification of the strains is difficult, as the larvae and male moths cannot be readily separated morphologically.

Molecular biology techniques have been used to show species and subspecies variation in many insects and have the advantage of applicability to larvae, pupae or adults. Several approaches have been tried with limited success, but, building on work by Pfeiffer et al. (1995), we have used amplification of ribosomal DNA and subsequent restriction enzyme digestion or sequencing to successfully distinguish between strains and hybrids of GM (Glare, Richards and Hall, unpubl. data). The study was conducted with insects from only four locations and needs to be confirmed with a larger sample group, but offers a potential method (tested in New Zealand) that should separate Asian and non-flight strains at all life stages.

\section{AGENTS FOR ERADICATION AND CONTROL}

In the case of GM establishing in New Zealand, an environmentally sound method of eradication and/or control will be required. As the pest has been in the USA and Canada for over 100 years, detailed information on agents and effectiveness is often available. The agents are summarised in Table 1.

\section{Diflubenzuron}

Better known under the trade name Dimilin, this insect growth regulator was used in $40 \%$ of GM treated area in the USA between 1990-1994. Although safer than broad spectrum chemical controls, there are some non-target effects on invertebrates and frequent applications (not recommended in the USA) would increase the residue risk. Bacillus thuringiensis var. kurstaki (Btk)

The bacterium Btk produces a toxin active against many Lepidoptera, including GM. Unlike most insect pathogens, it does not recycle in the insect and is used as an inundatively applied agent. Between 1980 and 1994, approximately 1.7 million ha were treated with $B t$ in the eastern USA for GM control (Reardon et al. 1994). Btk was also used in the eradication campaign against the tussock moth in Auckland. Nontarget effects are limited to Lepidoptera, but the development of host resistance can be a problem during long-term control efforts.

\section{Nucleopolyhedrovirus}

Lymantria dispar nucleopolyhedrovirus (LdNPV) is a specific virus which attacks only Lymantria spp. (Barber et al. 1993; Glare et al. 1995), making it one of the most specific agents available. It occurs as a natural control agent in most GM populations, but is also formulated as a product in several countries (Table 1). First registered in the USA in 1978, LdNPV is aerially applied on around 20,000 acres in the USA annually (Reardon and Podgwaite 1994). The virus is not registered for use in New Zealand; sufficient information has been obtained to apply for such registration. Currently, however, the supply of any "product" of suitable quality is limited.

\section{Entomophaga maimaiga (Entomophthorales: Zygomycetes)}

The fungus, E. maimaiga, is a GM pathogen originally from Japan; it has recently become a very effective classical control agent of GM in the USA (Hajek et al. 1995). In the field it is only recorded attacking GM (Reardon and Hajek 1993). As the fungus is difficult to culture in vitro, its use has been restricted to natural spread and inoculative releases by moving the resting spore stage to new areas in soil. All information gathered indicates the fungus would not be suitable for eradication procedures, but would have potential for release as a long-term control agent, should GM establish in New Zealand.

\section{Protozoa}

There is some potential for microsporidia as biocontrol agents for GM (Novotný 1988; Jeffords et al. 1989), but only as introduced agents as they cannot be mass-produced. Given the lack of complete specificity, protozoa would require host range testing before recommendation for release in established GM populations in New Zealand. 


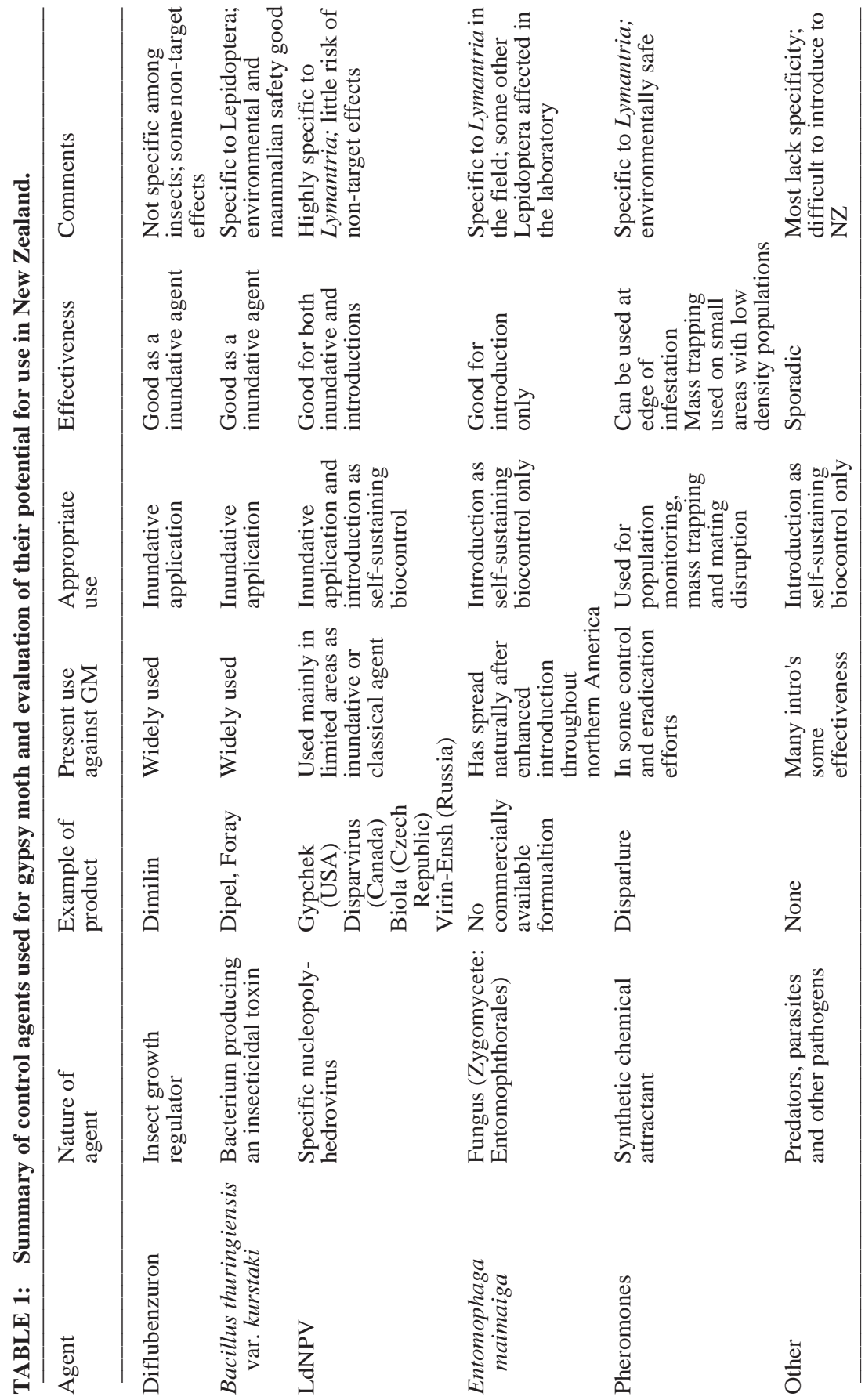




\section{Predators and parasites}

In some places, natural population regulation is thought to be due to the action of a group of parasites and/or predators. However, introductions into the USA have not resulted in significant population suppression (USDA 1995), and consideration of the literature suggests that parasites would be unsuitable for use in New Zealand because of cost, the requirement for alternate hosts and lack of specificity.

\section{Pheromone use}

A synthetic sex pheromone has been commercially produced for GM under the name "disparlure" and is highly specific for GM. It is used in monitoring but also offers two methods of population suppression: mass trapping and mating disruption. Mass trapping is usually used in conjunction with other methods of control and was the primary treatment in 20\% of eradication efforts in the USA between 1967 and 1993 (USDA 1995). Mating disruption was used in only 6 eradication attempts (out of 550) up to 1993 in the USA (USDA 1995), and is likely to be most effective against restricted populations where high dose levels can be maintained.

\section{MODELLING GYPSY MOTH IN NEW ZEALAND}

Following review of overseas models and population dynamics data, models were developed to predict the population dynamics of both EGM (equivalent to NAGM in all characteristics) and AGM in New Zealand in order to help in the development of control strategies (Barlow, Caldwell and Kean, unpublished). According to Barlow et $a l$., AGM is predicted to increase more rapidly than EGM at first, and then to maintain more widely fluctuating densities and more pronounced outbreaks, given the presence of predators functionally equivalent to those elsewhere in the moth's range. Under the model, predator pressures cause population fluctuations, therefore in the absence of predators in New Zealand, long-term population fluctuations are unlikely for AGM although populations would be high, especially in the first few years after introduction.

After a model of GM in New Zealand had been developed, Barlow, Caldwell and Kean examined the likely effects of control, using the LdNPV as the main control agent. In the short term (the year following application), suppression depends on the application rate of the spray and, because of the recycling of infection within the population, on the larval density at the time of application. The latter effect distinguishes LdNPV from Btk or other pesticides, whose proportional effect is usually densityindependent. Thus, $80 \%$ suppression of peak larval densities in the year following control can be obtained from an application of NPV at the standard rate $\left(2.5 \times 10^{12}\right.$ virus particles/ha), if the larval density is extremely high $\left(10^{5} / \mathrm{ha}\right)$ or extremely low (10/ha). This drops dramatically to a $30 \%$ reduction at a pest density of 100/ha. Timing of application within a year is also important. The model suggested a spray during maximum larval abundance gives twice the level of suppression in the following year as a spray when densities are lowest.

Assuming that the default parameters in the model are correct, eradication of a gypsy moth population with LdNPV is only possible if the population is very low (15 larvae/ha) and several sprays are used in rapid succession or the spray concentration is very high $\left(2.5 \times 10^{13}\right.$ virus particles/ha). Therefore, virus alone is unlikely to be a suitable choice for eradication. The model can be used to evaluate other potential eradication and control agents.

\section{STRATEGIES FOR ERADICATION}

If GM is found in New Zealand in a limited area, eradication is feasible. In the USA and Canada, "eradication" has been performed over 550 times, mainly in California, and is considered successful against small (under 40.5 ha), well-defined populations (USDA 1995). As with the white spotted tussock moth, decisions will need to be made between available control options. While these decisions require political and public input, it is possible to summarise strategies which can then be modified to suit the public/political climate. In our opinion:

- Btk would be the main eradication insecticide, especially for aerial application. Btk has the benefits of being widely available, has been used previously in many 
eradication procedures and kills GM effectively. The tussock moth programme has already established the safety and method of use over urban areas in New Zealand. Drawbacks are that it could decimate exposed Lepidoptera, which may in turn temporarily affect some bird life in the spray zone.

- The insect growth regulator, Dimilin, would be useful for ground application to control GM in densely infested areas. This chemical has more potential non-target effects, so use should be limited to specific ground applications.

- LdNPV, such as Gypchek (USDA), could be used early in an eradication programme, both as a knockdown agent and to establish virus in the population. If the infested area is an important lepidopteran conservation area, it may need to be the primary method for eradication. There appear to be no non-target problems associated with its use.

- Mass trapping may be a useful addition, especially around the edges of infestations as both a monitoring tool and to trap males to reduce mating opportunities.

- Other control measures, such as mating disruption, E. maimaiga and parasites are not suitable for eradication in most situations.

Data are available on $B t k$ and viral spray densities and timing of sprays required for eradication. In general in the USA, 2-3 applications, 2-7 days apart have been used in eradication procedures. However, control of AGM could be more difficult than NAGM or EGM, as egg hatch will occur over a longer period than non-flight GM, making the targeting of sprays against selected instars more difficult. Both virus and $B t k$ are more effective against younger instars which makes spray timing important. The modelling work has given some indication of optimal virus release times under New Zealand conditions, but this needs to be extended to Btk and other agents.

\section{STRATEGIES FOR CONTROL}

If GM establishes over a wide area or eradication is unsuccessful, then ongoing population suppression will be required and early introduction of a range of agents is desirable. We suggest that:

- LdNPV be introduced as soon as GM is found in New Zealand. Modelling of the effect of virus on AGM in New Zealand suggests that it would be an effective suppression agent (Barlow, Caldwell and Kean, unpubl.).

- The introduction of the fungus, E. maimaiga, should be investigated and, if it poses no threat to native insects, released as soon as is practical, as it has proved to be a very successful suppression agent in the USA.

- Btk is a single action insecticide in most cases and would not maintain itself in a GM population. It could be useful to protect specific areas such as stands of susceptible trees.

- Mass trapping and mating disruption using synthetic pheromone may be useful in slowing the spread at the front of a non-flight population of GM but would be of little use for flighted AGM established over a wide area.

- Parasites and predators from other countries are unlikely to be imported due to potential non-target effects, such as broad host range and the requirement for alternate hosts.

\section{CONCLUSION}

There are a number of agents which could be used to combat GM should it be found in New Zealand. Decisions on which of the agents should be used in particular circumstances will require some public discussion, but our view is that there are a number of agents which would be suited for various situations. Proactive, New Zealand-oriented research such as the full testing of molecular techniques to distinguish between GM strains, further development and use of models to investigate combinations of control agents and their optimum timing, assessment of the specificity of E. maimaiga and the effectiveness of pheromone, would expedite the use of controls should an introduction occur. 


\section{ACKNOWLEDGEMENTS}

Funding was provide by the Foundation for Research, Science and Technology under programmes C10 434 and C10 540. Discussions and access to unpublished data was provided by many GM researchers. In particular we thank Drs John Podgwaite, Jane Carter, Bill Wallner, Melody Keena, Norman DuBois and Mike Montomergy (US Forest Service, Hamden CT), Dr Ann Hajek (Cornell University, Ithaca, NY, USA), Drs Gisbert Zimmermann, Jurg Huber (director), Horst Baton and Gustav Langenbruch (BBA, Darmstadt, Germany), Dr Julius Novotny (Forest Research Institute, Banska Staivnica, Slovakia), Dr Furher, Dr Axel Schof and Gernot Hoch (Institut fur Forstentomologie, Forstpathologie und Forstschultz, Universtat fur Bodenkultur, Wien, Austria), Drs Martin Shapiro, Ed Doughety, Jean Adams, Dwight Lynn (Insect Pathology Laboratories, USDA/ARS, BARC-West, Beltsville MD, USA), Dr John Cunningham, Dr William Kaupp, Peter Ebling, Stephen Holmes, Dr Dave Tyrrell Dr G.M. Howses (Forest Pest Management Institute, Forestry Canada, Queen Street, Sault Ste. Marie, Ontario, Canada).

\section{REFERENCES}

Barber, K.N., Kaupp, W.J. and Holmes, S.B., 1993. Specificity testing of the nuclear polyhedrosis virus of the gypsy moth, Lymantria dispar (L.)(Lepidoptera: Lymantriidae). Can. Entomol. 125: 1055-1066.

Cowley, J.M., Bain, J., Walsh, P.J., Harte, R.T., Baker, R.T., Hill, C.F., Whyte, C.F. and Barber, C.J., 1993. Pest Risk Assessment for Asian Gypsy Moth, Lymantria dispar L. (Lepidoptera: Lymantriidae). New Zealand Forest Research Institute. Report prepared for MAF, NZ. 39pp

Glare, T.R., Newby, E.M. and Nelson, T.L., 1995. Safety testing of a nuclear polyhedrosis virus for use against gypsy moth, Lymantria dispar, in New Zealand. Proc. 48th N.Z. Plant Prot. Conf.: 264-269.

Hajek, A.E., Humber, R.A. and Elkinton, J.S., 1995. Mysterious origin of Entomophaga maimaiga in North America. Amer. Entomol. 41: 31-42.

Jeffords, M.R., Maddox, J.V., McManus, M.L., Webb, R.E. and Wieber, A., 1989. Evaluation of the overwintering success of two European microsporidia inoculatively released into gypsy moth populations in Maryland. J. Invertebr. Pathol. 53: 235-240.

Novotný, J., 1988. The use of nucleopolyhedrosis virus (NPV) and microsporidia in the control of the gypsy moth (Lymantria dispar, Linne). Folia Parasitol. 35: 199208.

Pfeifer, T.A., Humble, L.M., Ring, M. and Grigliatti, T.A., 1995. Characterisation of gypsy moth populations and related species using a nuclear DNA marker. Can. Ent. 127: 49-58.

Reardon R.C., Dubois, N. and McLane, W., 1994. Bacillus thuringiensis for managing gypsy moth: a review. USDA, Tech. Trans. FHM-NC-01-94, 32 pp.

Reardon, R. and Hajek, A., 1993. Entomophaga maimaiga in North America: a review. AIPM, Technology transfer. USDA For. Ser., Northeastern Area, NA-TP15-93. 22 pp.

Reardon R.C. and Podgwaite, J.D., 1994. Summary of efficacy evaluations using aerially applied Gypchek against gypsy moth in the USA.J. Environ. Sci. Health, B29(4): 739-756.

USDA 1995. Gypsy Moth Mangement in the United States: a Cooperative Approach. (draft environmental impact statement). USDA Forest Service, Washington DC. 